\title{
Reply to the correspondence letter 'Do true preretinal (subhyaloid) hemorrhages occur in infants?' by H. Gardner
}

\author{
David Taylor
}

Received: 26 October 2011 / Accepted: 8 November 2011 /Published online: 29 November 2011

(C) Springer-Verlag 2011

I am grateful for Dr, Gardner's interest in the article, his comments and I thank him for his trouble. Of course, I presume Dr. Gardner understands that I was not using the term pre-retinal to include all intraocular haemorrhages which might be inferred from his first sentence. I agree with much of what he says but would like to clearly distinguish what is seen clinically from pathological findings and adult findings with those in children. I cannot reliably distinguish clinically between subhyaloid and pre-retinal haemorrhages and thus lump them together.
The study of Coats et al. used rotational forces, not direct trauma, and the authors pointed out that extrapolation of their piglet model to the human infant should await further investigation. The majority of intraocular haemorrhages were located in regions of strong vitreous attachment which was why the article was cited but it only suggests that this model may be useful for investigating this finding.

David Taylor

D. Taylor $(\square)$

Paediatric Ophthalmology, University College London,

11-43 Bath Street,

London EC1V 9EL, UK

e-mail: d.taylor@ich.ucl.ac.uk 